\title{
Crisis de soberanía y militarización de la frontera norte. La fragilidad estatal ante la amenaza de los crímenes organizados en Argentina*
}

DOI: https://doi.org/10.18046/recs.i31.3724

\author{
Crisis of Sovereignty and Militarization of the \\ Northern Border. State Fragility in the Face of the \\ Threat of Organized Crimes in Argentina

\section{Sabina Frederic ${ }^{* *}$} \\ Universidad Nacional de Quilmes (Bernal, Argentina)/CONICET (Argentina)
}

\footnotetext{
${ }^{*}$ Los datos aquí analizados fueron obtenidos durante el trabajo de campo realizado en 2013, 2018 y 2019. Los dos primeros se produjeron en el marco de dos proyectos de investigación realizados en convenio con el Ministerio de Seguridad de la Nación, el primero suscrito con la Universidad Nacional de Quilmes y coordinado por la autora (2013-2014), y el segundo con CONICET/BID, dirigido por Brígida Renoldi (2018), y del cual la autora fue investigadora. En 2019 el trabajo de campo fue financiado por el proyecto de investigación científico tecnológico "El Estado y la seguridad pública: obediencia, desobediencia y autoridad en las fuerzas policiales y de seguridad de la Argentina contemporánea”, FONCyT Ministerio de Ciencia y Tecnología de la República Argentina y UNQ, bajo la dirección de la autora. Una primera versión de este artículo fue presentada en el Working Group: Critical Military Studies ERGOMAS (15th ERGOMAS Biennial Conference), en Lisboa, Portugal. Artículo de investigación recibido el 24.09.2019 y aceptado el 10.03.2020.

** Doctora en Antropología Social por la Universidad de Utrecht (Países Bajos). Profesora titular de la Universidad Nacional de Quilmes (Argentina). Investigadora independiente del Consejo Nacional de Investigaciones Científicas y Técnicas (CONICET) (Argentina). Correo electrónico: sabinafrederic2011@gmail.com ORCID: https://orcid.org/ooooooo1-7200-819X
} 


\section{Cómo citar/How to cite}

Frederic, Sabina (2020). Crisis de soberanía y militarización de la frontera norte. La fragilidad estatal ante la amenaza de los crímenes organizados en Argentina.

Revista CS, 31, 17-41. https://doi.org/10.18046/recs.i31.3724 


\section{Resumen}

El proceso de democratización iniciado en la década de 1980, una de cuyas caras fue la desmilitarización del Estado, comenzó a revertirse en los inicios del siglo XXI, con un ejercicio de soberanía donde la Gendarmería y las Fuerzas Armadas tendrían un lugar destacado. La investigación se propone dar cuenta de la continuidad entre gobiernos de signo político opuesto, en la enunciación de la fragilidad del Estado en la frontera norte argentina, donde las amenazas asociadas con el crimen organizado (narcotráfico y terrorismo internacional) degradaban la soberanía estatal. Desde una perspectiva etnográfica de los operativos que involucraron militares, mostramos cómo se constituyeron en garantes de una soberanía estatal amenazada. Argumentamos así que la conceptualización crítica del fenómeno como militarización de la seguridad interior se muestra limitada a la hora de entender la crisis de la soberanía en tiempos de devastación de la protección estatal.

PALABRAS CLAVE:

soberanía, militares, frontera

The demilitarization of the State, which was one of the faces of the democratization process initiated in the 1980 os, was reverted in the early twenty-first century, along with an exercise of sovereignty where the Gendarmerie and the Armed Forces would have a prominent place. The research intends to give an account of the continuity between governments of opposite political sign in the enunciation of the State's fragility in the northern border of Argentina, where the threats associated with organized crime (drug trafficking and international terrorism) degraded the State's sovereignty. From an ethnographic perspective of the operatives that involved the military, we show how they became guarantors of a threatened State sovereignty. We argue that the critical conceptualization of the phenomenon as militarization of internal security is limited in understanding the crisis of sovereignty in times of devastation of State protection.

\section{KEYWORDS:}

Sovereignty, Military, Border 



\section{Presentación: vulnerabilidad del Estado y militarización de la soberanía}

Durante los primeros veinte años del siglo XXI, en Argentina asumieron el poder estatal dos gobiernos de ideologías políticas proclamadas contrarias: el primero de centro-izquierda (kirchnerismo) y el segundo de centro-derecha (macrismo). Ambos identificaron en la frontera norte y en los grandes centros urbanos una creciente y peligrosa amenaza provocada por el crimen organizado y el narcotráfico. Aunque en un plano sus cosmovisiones sobre cómo acabar con esta amenaza variaron significativamente, menos variación encontramos en el lugar asignado a las Fuerzas Armadas para conjurar esos delitos en el territorio llamado frontera norte. Así, aunque el macrismo fue notablemente más violento en su narrativa y normativa, y se alineó expresamente a la agenda estadounidense contra el crimen organizado y el terrorismo internacional -cosa que el kirchnerismo no hizo-, hubo continuidades significativas. Estas continuidades -como argumentaré- parecen obedecer a una crisis de los Estados nacionales como único vehículo de ejercicio de la soberanía que las amenazas trasnacionales, reales o ficticias, no solo ponen en evidencia, sino que, por efecto de su enunciación, también acentúan.

Comparto en este sentido la perspectiva de Pilar Calveiro (2012), respecto de cómo esa crisis está unida al desmantelamiento del Estado del bienestar (Wacquant, 200o), y la deriva violenta que el Estado asume en algunos países como México, Colombia y Brasil. En el caso argentino, esa deriva se intensificó, a juzgar sobre todo por el crecimiento sostenido del $3 \%$ anual de la tasa de encarcelamiento durante el período kirchnerista y de un incremento del $6 \%$ durante el macrismo (Procuración Penitenciaria de la Nación, 2019; Sistema Argentino de Información Jurídica, 2019). La desmilitarización de la seguridad interior sostenida en la Ley de Defensa (1987) y la Ley de Seguridad (1991), desde fines de la década de 1980, excluyó a las Fuerzas Armadas de la tarea policial, lo cual, sin duda, puso un freno a la escalada de violencia institucional que encontramos en los países antes nombrados.

Por consiguiente, más que referirme a los frenos a la militarización de la seguridad interior en Argentina (Centro de Estudios Legales y Sociales, 2018; Sain, 2018), quisiera mostrar aquí cómo la presencia militar, ya sea de la Gendarmería o de las Fuerzas Armadas, ha sido un modo de ejercicio de la soberanía de Estado. Desde una perspectiva antropológica, resulta provechoso "explorar la soberanía de facto, por ejemplo, la habilidad de matar, castigar y disciplinar con impunidad donde se encuentre y practique, antes que la soberanía fundada en ideologías y reglas formales o en la legalidad" (Hansen; Stepputat, 2006: 396), como también explorar las tensiones y superposiciones en el ejercicio de la soberanía estatal, así como la brecha entre las formas narrativas e ideales y las efectivamente practicadas. 
El argumento es entonces que, con variaciones, el despliegue de las Fuerzas Armadas en apoyo de la Gendarmería, en la frontera norte, converge en la declaración de vulnerabilidad del Estado argentino en la frontera con Bolivia y Paraguay, por avance del narcotráfico y el crimen organizado. Ese discurso declaró y ratificó la fragilidad del Estado en uno de sus bordes, criminalizó a sus poblaciones y sentó una ground zero, que habilita la excepcionalidad (Agamben, 1998). Esta excepcionalidad no solo significa discrecionalidad, sino también prácticas y formas de ejercicio de la soberanía del Estado que se solapan, contradicen y superponen, mostrándose incompletas, inacabadas e insuficientes a la luz de los planes implementados.

Ahora bien, si desde una perspectiva crítica -o de denuncia-cabe subsumir el fenómeno bajo la categoría Militarización de la Seguridad y advertir, como Juan Gabriel Tokatlian (2017), sobre los riesgos y peligros para la ciudadanía y las propias instituciones que este fenómeno puede desencadenar, sobre todo cuando responde al esquema de guerra contra el narcotráfico, y las implicancias de tomar a una agenda global (o de Estados Unidos) que aplica recetas que interfieren en la soberanía nacional y regional; existe otra mirada. Se trata de dar cuenta de cómo el ejercicio de la soberanía es también un modo de administrar poblaciones (De Oliveira, 2014; Lima, 2002). El proceso de despliegue de los militares en la frontera norte fue un intento de restituir al Estado en Argentina en ese borde contra fuerzas clandestinas, como el narcotráfico o el terrorismo internacional, pero también contra los modos locales ya desbordados de su ejercicio. La retracción del Estado educador y sanitario, y aquel cuyas medidas protegían el desarrollo productivo en las fronteras, echó mano de las Fuerzas Armadas, más por su investidura al haber forjado la patria y su capacidad de gestionar poblaciones, que por su habilitación al ejercicio de la fuerza pública.

Dicho esto, revisaré una política de Estado a través de los operativos desplegados por la Gendarmería y las FF. AA. en territorio nacional durante los últimos años veinte años, que buscó renovar la confianza política en los militares argentinos, al recuperar su valor como productores míticos de soberanía. Cabe señalar que los datos resultan de sucesivos trabajos de campo etnográficos realizados en 2013, 2018 y 2019, y recoge también fuentes periodísticas.

\section{Remilitarizar la administración de poblaciones en los bordes}

A diferencia de otros procesos posautoritarios en América Latina, Argentina transitó un proceso de desmilitarización que debilitó a las Fuerzas Armadas, presupuestaria y simbólicamente. Democratización y desmilitarización fueron dos caras del modo 
en que el Estado y los ciudadanos tramitaron las atrocidades cometidas durante el terrorismo de Estado y la derrota en la Guerra de Malvinas, marcada por el activismo en derechos humanos a favor del juicio y castigo de sus responsables. Pero el derrotero de los gobiernos de las dos primeras décadas del siglo XXI, aún discontinuos entre sí, muestra signos antitéticos con esa etapa.

En este sentido, el gobierno de centro-izquierda (2003-2015), catalogado como posneoliberal por sus políticas de protección social (Kessler, 2013), sostuvo la demarcación legal entre seguridad y defensa excluyendo a las Fuerzas Armadas de la seguridad interior. También aplicó una política de democratización manteniendo la reducción presupuestaria iniciada con el fin de la dictadura (1983), desarrollando así la estrategia de evitar un nuevo golpe militar, la cual reforzó en 2006 reglamentando la Ley de Defensa Nacional (1987), para circunscribir la intervención de las Fuerzas Armadas en caso de que la amenaza procediera de un Estado extranjero. Por su parte, la política de derechos humanos para conjurar la repetición del Terrorismo de Estado que reinstaló la figura de los militares como victimarios, consiguió el procesamiento por delitos de lesa humanidad de cerca de 2000 militares, y la prisión de unos 1000, de los cuales 400, hasta 2019, aún estaban presos, otros habían fallecido en prisión y un último grupo había conseguido la prisión domiciliaria.

Al mismo tiempo que se producían los juicios a militares, comenzaron a cultivarse desde el Ministerio de Defensa los derroteros épicos de figuras de la historia militar, como el líder de la independencia nacional del siglo XIX, Manuel Belgrano, primero abogado y luego militar, y los generales Manuel Savio y Enrique Mosconi, comprometidos a comienzos del siglo XX con el desarrollo de la energía y la industria nacional, a favor de la soberanía del país. Esta revalorización-tibia para los militares en tanto no reivindicaba su carácter particular, la guerra y el combate- comenzaba a perfilarse en dicho gobierno de centro-izquierda, posneoliberal, que heredó la retracción del régimen de bienestar'.

En este período, al tiempo que continuaba la política estatal de debilitamiento de las Fuerzas Armadas, hubo otra novedad: el kirchnerismo fortaleció a la Gendarmería en presupuesto, personal y equipamiento. Esta fuerza militar intermedia, con competencias en defensa pero también en seguridad interior, dependió del Ejército argentino hasta 1984, compartiendo su código de disciplina². Mientras el Ejército vio

1. Una vasta literatura da cuenta de cómo los regímenes llamados neoliberales restringieron o desmantelaron la inversión pública en servicios (educación, salud, infraestructura, energía, etc.) bajo el criterio de que eran gastos. Este desfinanciamiento y privatización de servicios introdujo en Argentina mayor desigualdad y un deterioro de los mecanismos redistributivos de protección estatal.

2. En 2008, se aprobó el nuevo código de disciplina, se derogó el fuero militar y los tribunales de honor, y se introdujeron derechos para limitar la discrecionalidad jerárquica. 
disminuir su personal y perdía en oleadas a su personal más joven, la Gendarmería pasó, en una década (2003-2013), a triplicar el número de integrantes, de 17000 a 37 ooo. Finalmente, se invirtió la jerarquía al interior del Estado argentino entre Ejército y Gendarmería, a favor de esta última. Paradójicamente, esa fuerte carga negativa hacia los militares comenzó a desmontarse a partir de 2006, por obra del mismo gobierno de centro-izquierda que eliminó los indultos sancionados en la década anterior y construyó las bases jurídicas para que la justicia investigara, procesara y condenara a miles de militares acusados por delitos de lesa humanidad.

Respecto del gobierno posterior, Cambiemos (2016-2019), neoliberal por sus políticas de déficit estatal cero, liberación de las barreras arancelarias a la importación y apertura del mercado externo financiero, trajo un cambio de énfasis narrativo y normativo hacia el uso discrecional de la fuerza pública. Se inclinó a destacar la necesidad de dar vuelta a la página del pasado -dictatorial-y a defender la restauración de la reputación perdida por las Fuerzas Armadas durante los años anteriores. Este gobierno activó ciertas expectativas de los militares, cuyos mandos superiores tuvieron un lugar destacado en las negociaciones, accediendo a las máximas autoridades gubernamentales sin mediación de las del Ministerio de Defensa. Durante este mandato, se derogó la reglamentación de la Ley de Defensa por una nueva sancionada en 2018 que habilitó la intervención de las Fuerzas Armadas ante amenazas externas no estatales, como el narcotráfico y el terrorismo internacional.

Su sanción despertó fuertes críticas en el espacio político y mediático. Desde el amplio abanico del denominado progresismo, se convocó una protesta callejera contra la militarización de la seguridad interior. Se movilizaron: intelectuales, exfuncionarios del gobierno de centro-izquierda, referentes de organizaciones de derechos humanos, como Abuelas y Madres de Plaza de Mayo, y el Premio Nobel de la Paz, Adolfo Pérez Esquivel. Al temor por el regreso del terrorismo de Estado, se sumaron argumentos que destacaban las violentas consecuencias de la intervención de las Fuerzas Armadas en la seguridad interior en países de la región (Colombia, México y Brasil), la degradación que estas podrían sufrir y su ineficacia.

Aun con sus diferencias, que en un plano pueden ser notables, ambos gobiernos nacionales se caracterizaron por depositar en la investidura militar, fueran gendarmes o soldados, variaciones sutiles en el ejercicio de la soberanía territorial. Ambos buscaron apuntalar una soberanía asediada por nuevas amenazas, apelando así al imaginario social donde tuvieron un lugar emblemático en la fundación del Estado nación moderno. Ya no serían requeridas para la intervención armada, por supuesto, pero sí buscarían restituir el principio de administración de poblaciones. Sorprendentemente, aunque la retórica del gobierno de centro-derecha en seguridad fue más agresiva e incluso produjo mayor letalidad de las fuerzas policiales, 
su operativo militar fue más inocuo que los implementados durante el gobierno de centro-izquierda.

Como mostraré, esta paradoja se puede entender por la emergencia de una concepción de los altos mandos del Ejército sobre el ejercicio de soberanía, forjada en su experiencia durante la operación de paz en Haití, y reconocida por las autoridades civiles del gobierno de centro-derecha. Justamente, el Operativo Integración Norte (OIN), lanzado en 2018, último diseño en este proceso, expresa esa búsqueda. Por consiguiente, clasificar estos despliegues como militarización de la seguridad no deja traslucir cómo las Fuerzas Armadas son puestas en escena también para rectificar una soberanía que se declara amenazada o debilitada.

\section{Frontera norte, frontera colador}

Al menos desde mediados de la década de 1990, ciertos medios periodísticos y gobiernos insistieron en diagnosticar el límite con Bolivia, Paraguay y Brasil como el sitio de entrada de drogas ilícitas, y ligarlo a otro tipo de tráficos ilegalizados. Así, la frontera norte fue instalándose como una categoría válida para denominar negativamente aquel territorio, que quedó representado como una zona donde el Estado había perdido la capacidad de hacer cumplir la ley y, sobre todo, la eficacia para controlar el flujo de personas, mercaderías, hasta ser el sitio donde el narcotráfico, el crimen organizado y el terrorismo internacional se conjugaban. Esta visión nunca estuvo anclada en un diagnóstico preciso, como ya ha sido señalado por los especialistas (Souto-Zabaleta; Delfino; Sarti, 2019; Tokatlian, 2017), y ni siquiera los datos sobre contrabando se encuentran ratificados por organizaciones estales, sino por redes de empresarios privados, tal como la Alianza Latinoamericana Anticontrabando, creada en 2016 y liderada por la Asociación Nacional de Industriales de Colombia, quienes constituyen un importante factor de presión sobre los gobiernos nacionales y para quienes el mayor tráfico ilegal es el de tabaco.

Ahora bien, aún sin diagnóstico preciso, la noción de frontera norte se fue naturalizand y a sociando a la de frontera colador o frontera caliente. Sin embargo, la apreciación que las fuerzas de seguridad y el Ejército tuvieron del territorio no lo hizo un sitio homogéneo, aunque se acordara en la existencia de una zona caliente ubicada en las provincias de Salta y Misiones (frontera con Bolivia, Paraguay y Brasil). En rigor, esa frontera, de 773 km compartidos con Bolivia; 1669 km, con Paraguay; y 1132 km, con Brasil, recorría problemáticas disimiles y escenarios socioculturales, muy cambiantes.

Pese a la coexistencia de narrativas contrapuestas y a la ausencia de datos confiables que permitieran ratificar la idea de que la frontera norte era el sitio principal 
de ingreso de drogas ilegalizadas, la idea de su peligrosidad fue creciendo ${ }^{3}$. Esta idea ha estado completamente arraigada entre gobernantes de todo el arco político, así como entre quienes habitan las ciudades de frontera, como La Quiaca, Aguas Blancas y Salvador Mazza. Sin embargo, al profundizar en esta apreciación durante el trabajo de campo acerca de los hechos concretos de inseguridad experimentados por los pobladores, no hay ninguna referencia a sucesos asociados con la violencia y el crimen organizado, solo a robos y hurtos menores. En buena medida, parece haber contribuido, a aquella caracterización, la extendida señal de cable que posee también en esa zona la cadena TN, propiedad del Grupo Clarín, la corporación de medios de comunicación más poderosa de la Argentina y emitida desde la capital del país, sociocultural y geográficamente distante $(1800 \mathrm{~km})$ de la frontera. También pertenecía a ese medio de comunicación Jorge Lanata, uno de los periodistas estrella de la televisión argentina. En varias emisiones de su programa Periodismo para Todos, este periodista se dedicó a dar cuenta del problema de las fronteras sin control, mostrando las imágenes del movimiento de personas cargando grandes bultos, mientras dramatizaba el supuesto tráfico de migrantes chinos, y denunciaba la omisión y negligencia de todas las agencias del Estado (Gendarmería, Aduana, Migraciones).

De este modo, la frontera norte, antes que un territorio de integración regional -concepto de cierto impacto en Sudamérica durante la primera década del siglo XXI por la expansión del Mercado Común del Sur (Mercosur) y la limitación del avance de los intereses norteamericanos-, se convirtió en un espacio de ilegalismos (Renoldi, 2015). El tránsito incesante de personas ${ }^{4}$ y mercaderías, sobre todo en Salta y Misiones, más la constatación de los habitantes argentinos de esa frontera norte, de que las ciudades de los vecinos países, particularmente Bolivia, se expandieron en infraestructura mientras las suyas no, fortalece la percepción de la degradación nacional en ese borde.

3. Los datos disponibles de acceso público con los cuales los gobiernos tratan de probar tanto su eficiencia como el hecho de que su diagnóstico sobre la frontera norte es acertado, son decomisos de marihuana y de cocaína. Pero, en rigor, estos no permiten determinar si resultan de mayor actividad policial o de mayor tráfico (Souto-Zabaleta et al., 2019).

4. Según la Dirección Nacional de Migraciones (s.f.), en 2017, las ciudades de Aguas Blancas, Salvador Mazza, La Quiaca y Puerto Iguazú ocuparon los puestos $7 .^{\circ}, 5^{\circ}, 14 .^{\circ}$ y $2 . .^{\circ}$, respectivamente, en ingreso de población registrada. 


\section{Operativos con militares en la frontera norte}

La Argentina cuenta con la Gendarmería, dedicada a administrar la circulación en sus bordes territoriales desde mucho antes que la amenaza narco y del crimen organizado adquiriesen el tenor actual. Autorreconocida con el nombre de Centinelas de la Patria, desde su creación en 1938, su misión fue el control de la frontera y la seguridad en poblaciones aisladas y rutas nacionales, como reemplazo del Ejército. Su carácter militar responde a esa potestad para administrar poblaciones y ejercer soberanía en los límites territoriales del Estado nación y no solo al hecho de haber pertenecido al Ejército argentino (1958-1984). Las leyes de Defensa, de 1987, y de Seguridad Interior, de 1991, ratificaron esa condición, asignándole el carácter de fuerza intermedia con funciones, en la defensa nacional, de apoyo a la fuerza terrestre en tiempos de guerra.

Escuadrones, secciones y puestos de guardia son el sitio de vigilancia de los centinelas. Ocupados en identificar y reprimir delitos federales como son el tráfico de drogas, de personas y de mercaderías ilícitas, ejercen su poder de policía en rutas nacionales, ríos y caminos secundarios, donde patrullan y vigilan. Cuentan con una rutina de control en puentes y vías de acceso, así como operativos de patrullaje a supuestos infractores que cruzan el límite fronterizo por espacios de tránsito no autorizados.

Pero esa forma de ejercicio de la soberanía parece haber quedado superada en la frontera caliente y porosa, como los medios de comunicación masiva, los sucesivos gobiernos y la propia Gendarmería denominan al sitio de contacto con Bolivia y Paraguay, y donde el tráfico ilegal es más intenso. Es en ese vacío donde la presencia de las Fuerzas Armadas es invocada, y la Gendarmería, impotente, sobrepasada. Si bien el argumento para explicar esa impotencia ha sido la reducción de personal en dicha jurisdicción, enviado a patrullar zonas urbanas, la dinámica de los tráficos ilegalizados es tan oscura e intangible que se considera que la presencia de las Fuerzas Armadas daría más seguridad.

Así, en esos operativos militares encontramos recurrencias. Primero, observamos las amenazas globales del narcotráfico y el crimen organizado, materializadas esporádicamente en la exhibición mediática de grandes decomisos de marihuana y cocaína. Esas operaciones con nombres rimbombantes son eficaces recursos narrativos para justificar el despliegue de soldados, la inversión en tecnologías de vigilancia y el asedio permanente hacia poblaciones segregadas del mercado formal de trabajo (Calveiro, 2012). Segundo, expresan la vulnerabilidad de ciertos territorios donde el Estado habría perdido soberanía, y exhibe su fragilidad a la hora de imponer reglas y sanciones. Tercero, el recurso a la tecnología de avanzada (radares, drones y cámaras de seguridad) gestionada en el territorio por militares-en ambos gobiernos-, 
impulsó la producción de una forma de ejercicio de la soberanía sin la visibilidad de los funcionarios uniformados. A continuación, identificamos estas continuidades en la discontinuidad como rectificaciones en el ejercicio de la soberanía nacional en la frontera norte.

\section{Patrullas de observación y tecnología nacional}

El primer operativo militar fue el Fortín I. El gobierno de centro-izquierda desplegó, en 2006, operadores de radares de la Fuerza Aérea y el Ejército, sin patrullas. Introdujo a las Fuerzas Armadas en apoyo a la seguridad interior por primera vez en democracia. Recibió críticas de sectores de izquierda y algunos expertos, resistidas por el gobierno de entonces con el argumento de que el apoyo logístico sí estaba habilitado por la Ley de Seguridad. Pero estas críticas fueron apaciguadas por el valor atribuido a los radares de largo y corto alcance de producción nacional, elaborados por Investigaciones Aplicadas Sociedad del Estado (INVAP). Así, el control territorial por parte del Estado se reivindicaba en la soberanía tecnológica.

Cinco años más tarde, en 2011, el Ministerio de Defensa lanzó los operativos Fortín II y Escudo Norte, para fortalecer el control del espacio aéreo. Las Fuerzas Armadas desplegaron más radares, 20 unidades RASIT de corto alcance, modernizados todos por INVAP, dos aviones Pucará, cinco helicópteros, pero en esta oportunidad también se desplegó personal militar del Ejército y la Fuerza Aérea. En su lanzamiento, la entonces presidente, Cristina Fernández de Kirchner, destacó la importancia del uso de tecnología nacional y, respecto al narcotráfico, reflexionó: "Están allí donde no llega el Estado, esta lucha tiene dos frentes: uno militar y otro político, social y económico" ("Un escudo contra los narcotraficantes", 2011). Como se observa, su discurso declaraba la presencia del crimen organizado y el narcotráfico, al tiempo que anunciaba la existencia de un espacio donde el Estado no llega, donde este abandonó el ejercicio de la soberanía, y que explicaría su usurpación o disputa por parte de esas amenazas clandestinas. Cabe señalar que la elección de la categoría Fortín que nombra estos operativos, proyectaba al presente la fortaleza militar que en el siglo XIX fuera instrumento de la gestión represiva y civilizatoria de la población aborigen, con el fin de extender la soberanía estatal, o la frontera con el indio (De Jong, 2015; Ratto, 2003), al tiempo que se erigía el Estado Nación.

En cuanto al operativo Escudo Norte, fue la contracara del operativo Cinturón Sur ${ }^{5}$ que demandó el traslado de 1200 gendarmes de las fronteras hacia los barrios más empobrecidos de la ciudad de Buenos Aires. En rigor, el gobierno lo presentó 
como un operativo diseñado por el Ministerio de Seguridad que se articularía con el Fortín II y sería conducido por el Ministerio de Defensa. El Escudo Norte involucró 6ooo efectivos, entre gendarmes y prefecturianos, y 800 efectivos de fuerzas especiales y antidrogas de ambos grupos, además de helicópteros y embarcaciones "para combatir el narcotráfico, la trata de personas y el contrabando en las zonas del Noroeste Argentino y el Noreste Argentino" (Ministerio de Seguridad, 2011).

Dos años después, en 2013, el mismo gobierno reforzó el operativo Fortín II anunciando el envío de 4500 militares a la frontera norte. El despliegue fue en contingentes que rotaban cada 30 días. El personal cobraba un viático que oficiaba como estímulo, aunque al año se podían leer denuncias anónimas por demoras en su pago, en sitios de internet como zona militar ${ }^{6}$. El rol de los militares era patrullar, observar y transmitir información a la Gendarmería. En un acto público, la presidente Fernández de Kirchner justificó la decisión de tamaño despliegue de personal del Ejército destacando la vulnerabilidad del Estado en ese territorio y ubicando a las Fuerzas Armadas como recurso subsidiario de las de seguridad:

No tiene mucho sentido tener (...) regimientos en pleno centro de nuestras ciudades y tener nuestras fronteras que sean verdaderos coladores. Entonces creo que allí, las Fuerzas Armadas pueden cumplir un rol más que importante en colaboración directa con nuestras Fuerzas de Seguridad. (Gallo, 2013)

Si algo estaba claro ya en mayo de 2013, en una visita de trabajo de campo que hiciera a la zona, era la impotencia de los gendarmes al ver pasar a metros de sus puestos de control, por caminos alternativos, a cientos de bagayeros cargando bultos de alrededor de $80 \mathrm{~kg}$ con mercadería de contrabando, sin poder evitarlo; el tráfico había desbordado por su masividad y por la legitimidad alcanzada en una región donde las fuentes de empleo escaseaban.

\section{Emergencia en seguridad, tecnología extranjera y habilitación en el uso de la fuerza pública}

El cambio de signo partidario del Gobierno nacional no alteró significativamente la distribución de la fuerza pública dejada por el gobierno de centro-izquierda. Pero sí cambió la virulencia de su discurso contra el narcotráfico y el crimen organizado, así como la sanción de normativas de distinto estatus jurídico que promovieron el uso de la fuerza criticada por su parentesco con la política fallida y brutal de la guerra 
contra las drogas. El primer ejemplo en el campo que nos ocupa fue la sanción de un protocolo que autorizaba el derribo de aviones en vuelos clandestinos. Este se aprobó en el marco del Decreto Presidencial 228/2016, que declaraba la Emergencia en Seguridad Pública a comienzos de 2016, y se prolongó hasta 2019. Con él, se sustituyó el operativo Escudo Norte contra el avance del narcotráfico y se creó en su lugar el operativo Fronteras, que en rigor solo se aplicaba a la frontera norte. El decreto señalaba que el operativo era de carácter permanente. Su Artículo $4 .^{\circ}$ establecía:

\section{CONTROL MATERIAL Y TECNOLÓGICO DE LA ZONA DE FRONTERAS. Dispó- nese en forma inmediata la adopción de las medidas necesarias para la adquisición de los dispositivos técnicos materiales y tecnológicos de la Zona de Fronteras, conforme las necesidades operativas que disponga el MINISTERIO DE SEGURIDAD sobre la Zona de Frontera con relación a los objetivos establecidos por el presente Decreto sobre el delito complejo y organizado.}

Hubo otra diferencia significativa: era difícil, por entonces, encontrar militares que aceptaran involucrarse en la lucha contra el narcotráfico, porque para ellos se trataba claramente de una amenaza a la seguridad interior, un tema policial. Pero no ocurría lo mismo con el terrorismo internacional. El gobierno de Cambiemos sumó a la amenaza narco la del terrorismo internacional, mezclándolas con el crimen organizado. El gobierno anterior había resistido aceptar dicha amenaza que consideraba propia de una agenda favorable a los intereses de Estados Unidos.

La fundamentación del Decreto del Poder Ejecutivo Nacional 228/2016 declaró la Emergencia en Seguridad y amplificó la amenaza, estableciendo como objeto, en su Artículo 1. ${ }^{\circ}$, "revertir la situación de peligro colectivo creada por el delito complejo y el crimen organizado, que afecta a la República Argentina, por el término de trescientos sesenta y cinco (365) días corridos". Luego, definió delito complejo y crimen organizado, haciendo confluir: producción, tráfico y comercialización de estupefacientes, contrabando de armas, asociación ilícita calificada o terrorista o con fines políticos o raciales, fraude contra la Administración Pública, prostitución de menoresy pornografía infantil, financiación del terrorismo y trata de personas. El decreto, en su segundo título, denominado "Operativo fronteras y fortalecimiento del control de puertos, hidrovías y mar argentino", introdujo primero la urgencia de disponer de nuevas tecnologías de control en la zona de fronteras y declaró entonces el fracaso del operativo Escudo Norte. Pero en su Artículo 5. ${ }^{\circ}$ ratificó la política de ejercicio de la soberanía a través de la operación de radares iniciada por el gobierno anterior, al establecer que "dispondrá las medidas necesarias a fin de garantizar que la radarización de la Frontera Norte permita un eficiente control y una efectiva disponibilidad 
de información en relación con la ocupación y tránsito diario que se despliegue dentro del espacio aéreo soberano".

La inversión en tecnología se incrementó respecto a la del gobierno anterior y cambió el sentido del ejercicio de la soberanía basada en el uso de tecnología de producción estatal nacional. El gobierno de centro-derecha desplazó, en un primer momento, el despliegue masivo del Ejército por mayor inversión tecnológica producida por Israel: cámaras, escáneres, drones y torres de monitoreo y vigilancia. El valor soberano de la producción nacional de tecnología quedó así desmontado.

Por consiguiente, máquinas -antes que personas- fueron el esquema inicial del ejercicio de soberanía, aunque su origen fuera trasnacional. Esa tecnología proyectaba un poder imaginario, fantasmagórico, donde el Estado miraba a personas que cruzaban los márgenes, y ya no solo a vuelos clandestinos. En palabras de la ministra de Seguridad (2015-2020), Patricia Bullrich, en el acto de inauguración del sistema de vigilancia inteligente de fronteras, al expandir el programa Fronteras Seguras a la provincia de Salta, en Aguas Blancas: "Es el comienzo de una era distinta para Salta y el país que nos permite mirar más allá de los ojos de nuestros hombres" (Gaik-Aldrovandi, 2019).

En referencia a lo anterior, cabe señalar que la prueba piloto había llegado dos años antes, en 2017, a La Quiaca, separada de Villazón (Bolivia) por un río posible de cruzar a pie. Un $20 \%$ del personal del escuadrón con asiento en esa ciudad fue capacitado en Buenos Aires y luego enviado a la sala de monitoreo. Luego se extendió a tres puntos calientes de esa frontera: Aguas Blancas y Salvador Mazza, en Salta, y Puerto Iguazú, la triple frontera (Argentina, Paraguay y Brasil), en Misiones. Pero el tráfico de personas y mercaderías, lícito e ilegalizado, variaba mucho en cada ciudad de la frontera, y era bastante previsible que, en algunas, como Aguas Blancas, el volumen visible de personas (bagayeros trabajadores de frontera) que no cruzaban por los pasos autorizados era tan ostensible que este tipo de tecnología resultara absurda. Aun así, se inauguró el dispositivo tecnológico junto a un régimen simplificado para legalizar el tránsito de mercadería que alrededor de 2000 bagayeros $^{7}$ transportan cotidianamente. Sin embargo, el acto de lanzamiento de ese régimen con presencia de las autoridades nacionales, realizado en marzo de 2019 en Aguas Blancas, terminó con la ministra, el gobernador de la provincia y el jefe de Gendarmería Nacional apedreados por los bagayeros, supuestos beneficiarios del nuevo plan.

7. No hay un número preciso. Al tratarse de una actividad criminalizada, el Estado no ha hecho un registro oficial. Sin embargo, estos trabajadores se agrupan en cooperativas y declaran un total de 5000 personas. 
Ya en La Quiaca, donde el tránsito de personas era menos fluido, el dispositivo tecnológico no habría resultado eficaz para los gendarmes. Las cámaras, drones y escáner no alcanzaban a ejercer la vigilancia esperada sobre personas y terreno en los confines del territorio nacional. El personal superior de Gendarmería destacaba cómo las redes de confianza de la población local, así como la diferencia étnica entre gendarmes y población andina, jugaban en su contra. Era fácil identificarlos, aunque anduvieran de civil, las y los nativos(as), se avisaban rápidamente si se movilizaban desde el escuadrón hacia el río, cuando el área de monitoreo disparaba una alerta. Por otra parte, la población rural se quejaba ante la falta de patrullaje al jefe de Gendarmería, a quien responsabilizaba por el robo de ganado, el delito más habitual. Mientras aquel no tenía forma de responder a esta demanda, ya que quienes patrullaban ahora se ocupaban del monitoreo en una sala con pantallas conectadas a las cámaras que vigilaban las personas que cruzaban la frontera caminando por el río La Quiaca/Villazón. De manera que esa forma idealizada de ejercicio de la soberanía mediante videovigilancia era localmente impugnada, como lo fue más brutalmente en Aguas Blancas.

\section{Rectificación al ejercicio de la soberanía: el operativo Integración Norte}

De todos los operativos que involucraron a las Fuerzas Armadas, el más peculiar fue Integración Norte (OIN). El gobierno de Cambiemos había confiado más en la tecnología de vigilancia y en la Gendarmería, pero finalmente echó mano del despliegue de efectivos, particularmente del Ejército. El Estado Mayor Conjunto (EMCO) convenció al Gobierno de una alternativa al ejercicio de soberanía. En julio de 2018, se anunció un primer contingente de 500 efectivos, que sería reforzado en los sucesivos meses hasta alcanzar los 1500. Antes, como señalamos, el Gobierno nacional modificó el Decreto 683/2018, que reglamentaba la Ley de Defensa de manera que las Fuerzas Armadas estuvieran habilitadas para intervenir frente a una amenaza no estatal: narcotráfico y terrorismo internacional.

La crítica progresista no detuvo ni el cambio normativo ni el despliegue; sin embargo, el diseño del OIN estuvo lejos de guiarse por ese nuevo decreto. Los generales del EMCO se opusieron a convertirse en policías, demostrando a las autoridades políticas que la Ley de Seguridad vigente se los impedía. A cambio, propusieron un operativo que recogía una experiencia trasnacional: la Misión de Naciones Unidas de Estabilización de la Paz en Haití (Minustah), adaptada al contexto local. El Ejército llevaba, por los menos, una década de readecuación asistemática, informal, de su 
doctrina militar de la Guerra Fría a la de la posguerra fría. La experiencia de once años (2004-2015) en la Minustah les había mostrado que el recurso táctico del apoyo a la comunidad (distribución de alimentos, construcción de puentes, negociación en conflictos, organización de partidos de fútbol y fiestas), para ganar legitimidad en la población de Gonaïves y aislar a las bandas criminales sin usar la fuerza, era una fuente de soberanía (Frederic, 2019) capaz de aplicarse al territorio nacional.

Mientras las movilizaciones políticas contra el OIN denunciaban el regreso al pasado del terrorismo de Estado y la Doctrina de Seguridad Nacional de la Guerra Fría, para los militares el ambiente operacional donde aplicar este operativo era bien distinto. Se alejaba del de la Guerra Fría y del mandato de convertir a los militares en agentes de seguridad, como ocurría en Brasil, México y Colombia. Justamente, la experiencia de la Minustah hizo de la frontera norte un ambiente operacional donde poner las lecciones aprendidas en Haití al servicio del ejercicio de la soberanía nacional.

El OIN fue diseñado por un grupo de generales del Ejército argentino para dar presencia al Estado, un modo de ejercer soberanía dando seguridad, sin repetir ni copiar experiencias domésticas o trasnacionales trágicas y fallidas. Uno de ellos fue el general Jorge Duarte, jefe de uno de los batallones en Gonaïves. Algunos años antes, como integrante del área de operaciones del EMCO, Duarte había sistematizado las lecciones aprendidas de la Minustah. Por entonces, junto a una colega, habíamos iniciado una investigación sobre las experiencias de los militares argentinos, que en su segunda etapa contó con apoyo del Ministerio de Defensa (Frederic; Hirst, 2016). Nuestros intereses convergieron. El general Duarte facilitó el trabajo de campo e intervino leyendo los primeros borradores. En mis comunicaciones posteriores con Duarte, sus menciones a nuestro libro sobre Haití, La Presencia Argentina en Haití. Contexto global, regionaly experiencia militar, lo señalaban como su fuente principal de información.

La presentación de nuestro libro fue un evento significativo al revelar esa forma de ejercicio de la soberanía y propiciar su transmisión a la máxima autoridad del EMCO. Al evento había asistido Roberto Costa, un general ya retirado con quien teníamos confianza, como con el entonces jefe de EMCO, quien había sido su subordinado tiempo atrás. Costa había quedado sorprendido por nuestro hallazgo: la producción por parte del Batallón Conjunto Argentino (BAC) de una autoridad legítima para la población haitiana en un ambiente de ausencia estatal. Fue así que concertó una reunión con el jefe del EMCO, donde profundicé el tema de cómo sucesivos BAC en Gonaïves, hasta el terremoto de 2010, habían encarnado al Estado sin hacer uso ostensivo de la fuerza.

El OIN se lanzó dos años después de aquel encuentro en el EMCO. Sus máximas autoridades habían encabezado una dura negociación, en 2018, donde consiguieron 
imponer su propuesta contra aquella que ordenaba el Ministerio de Seguridad. Aunque no dependían de este, sino del Ministerio de Defensa, la ministra de Seguridad ejercía su autoridad de hecho. Esa negociación fue extremadamente dura y tensa -según nos relataron- y estuvo marcada por el desfinanciamiento más profundo respecto del PBI de las últimas 3 décadas, y por dos iniciativas gubernamentales resistidas por los militares: la venta de inmuebles de las Fuerzas Armadas para alimentar el presupuesto nacional y la transferencia en forma permanente de 5000 efectivos del Ejército a la Gendarmería. Una amenaza masiva de militares del cuadro superior que pedirían su pase a retiro, si el Gobierno no desistía de la medida, y la negativa a desfilar el día del aniversario de la independencia nacional frenó un mayor desguace institucional.

En ese escenario de deterioro presupuestario, de parálisis de las Fuerzas Armadas y de decepción de los militares hacia el gobierno de centro-derecha, el EMCO puso sus condiciones al OIN: se negó a asumir competencias operacionales con funciones policiales contrariando las órdenes que les llegaban desde el Ministerio de Seguridad. A cambio, convirtieron el ambiente operacional del OIN, dominado por la presencia del Estado, en uno apto para adiestramiento, apoyo logístico a las fuerzas federales y apoyo a la comunidad. Por consiguiente, aunque las Fuerzas Armadas comparten doctrina trasnacional, no puede explicarse este despliegue atribuyéndoselo a la participación de nuestros militares en cursos dictados por el Comando Sur8.

El carácter del OIN quedó enunciado en la Resolución del Ministerio de Defensa 818/2018, donde se estableció que la Argentina "debe contar con la capacidad de anticipar, disuadir y superar las amenazas, riesgos y desafíos del siglo XXI que afecten la seguridad nacional"; que las Fuerzas Armadas poseen capacidad para ejercer "una vigilancia efectiva de los espacios terrestres de interés, mediante una disuasión por presencia"; y que, por las características especiales de adiestramiento militar, "está bien preparado para brindar diversas acciones de apoyo a la comunidad". Aunque pudieran parecer ideas inconexas, su coherencia derivaba de la experiencia del ejercicio de una autoridad legítima en la Minustah y de la construcción de soberanía con solo mostrar los dientes y sin hacer uso efectivo de la fuerza.

Por consiguiente, podemos decir que la influencia de la experiencia de la Minustah sobre los militares, a la que Argentina aportó cerca de 13 ooo efectivos, estuvo condicionada a procesos políticos domésticos. Incluso si lo pensamos en términos de su contribución a la democratización, también nos inclinamos por combinar esas experiencias con la de los procesos domésticos. En este sentido, consideramos

8. Hay que cuidar las derivaciones automáticas a las que pueden dar lugar las menciones sobre la participación de nuestros militares en cursos dictados por Estados Unidos, tal como las encontramos en medios periodísticos, artículos y libros académicos. 
que esta perspectiva puede ampliar la argumentación más restringida de Arturo Sotomayor (2013), quien cuestiona el mito democratizador de las misiones de paz sobre las Fuerzas Armadas de Chile, Argentina y Brasil, atendiendo solo a sus desempeños extraterritoriales. El caso argentino muestra que deben ser incorporados los procesos políticos nacionales hacia los militares. En Argentina, el juicio a unos 2000 militares por delitos de lesa humanidad, iniciados en 2004, por los crímenes cometidos durante la dictadura de los años setenta, jugó un papel clave en el diseño de estos operativos sin uso de la fuerza, en territorio nacional.

Por consiguiente, el propósito del OIN era la disuasión por presencia en territorios imaginados como vulnerables, por la precariedad de la vida y la penuria económica, donde se asumía que la amenaza narco era mayor, porque la opción de entrar en el negocio ilegal era más probable allí donde el Estado era frágil. En este ambiente operacional se ubicaron los militares para ofrecerse como la encarnación del Estado nacional y, a través suyo, fortalecer agencias estatales provinciales más débiles. El Ejército aportaría con sus recursos-simbólicos, más que materiales-al ejercicio de la soberanía estatal frente al crimen global, en un territorio tradicionalmente ligado en la narrativa nacional a gloriosas batallas por la independencia y la liberación del yugo español en el siglo XIX. Allí, donde el respeto por los militares y su reconocimiento -según ellos mismos- contrastaba con su desprestigio entre pobladores de los grandes centros urbanos.

Como en Haití, la presencia del Estado a través del Ejército era entendida como un factor disuasorio a la supuesta penetración del crimen. Pero a diferencia de Haití, las reglas de empeñamiento del OIN fueron otras, ya que su misión en la frontera norte era adiestrarse y apoyar a la Gendarmería con la información producida por los radares. Protegido por el secreto militar, con esas reglas el Ejército puso freno a una orden del Gobierno que pedía que actuaran de acuerdo al Artículo 284 del Código Penal argentino, que obliga a cualquier ciudadano a reprimir delitos en flagrancia.

\section{El ambiente operacional: restauración de la soberanía en los bordes}

El ambiente en el que el Ejército diseñó el OIN conjugaba el hallazgo de una renovada capacidad de ejercer soberanía en un territorio donde el Estado se había declarado ausente, frágil o con poca llegada. Desde la perspectiva de aquellos generales del EMCO, ese ambiente que el Estado argentino había dejado a la intemperie debía ser reconquistado. Este ejercicio de la soberanía de Estado practicada por militares tenía por objeto frenar el dominio del narcotráfico en ese territorio, ganando legitimidad 
entre sus pobladores, en un "ambiente social de mucha necesidad", según me señaló el general Duarte (comunicación personal, 06.11.2018), ausencia de oportunidades laborales y escasa llegada de las instituciones estatales. El concepto táctico que proyectaban se basaba en las operaciones psicológicas ${ }^{9}$, aplicadas al comienzo de la Minustah o Comunicación Social Asociada al Combate (Cosaco). De acuerdo con la doctrina, a través suyo, las Fuerzas Armadas ganan legitimidad en la población e impiden cualquier cooperación o alianza con las fuerzas enemigas, ubicadas, durante la Guerra Fría, en la guerrilla insurgente apátrida y, posteriormente, en el terrorismo, el crimen organizado y el narcotráfico.

Ahora bien, cuando se conoció la noticia del OIN en La Quiaca, límite con la ciudad boliviana de Villazón, los pobladores se sintieron amenazados y atemorizados. El recuerdo del terrorismo de Estado en la década de los setenta golpeó la memoria social. Hubo detenidos, desaparecidos y un centro clandestino de detención en el Escuadrón de Gendarmería núm. 21, actualmente sitio oficial de memoria. Muchos de los desaparecidos eran trabajadores y delegados sindicales de un yacimiento minero próximo. Según nos relató una militante política y empleada municipal, tuvieron que salir a explicar a la gente y, especialmente, a las comunidades indígenas, que la presencia de los militares era para "ayudar a la comunidad". Ese fue también el contenido de una de las primeras notas periodísticas con las que se difundió la tarea del Ejército en la frontera norte, como el mensaje de WhatsApp con el que el general Jorge Duarte me contó otras actividades de apoyo a la comunidad que se realizarían en la región de frontera con Paraguay, en noviembre de 2018.

Cabe señalar que Duarte hacía una clara distinción entre la operación en Haití y el OIN en territorio argentino, al señalar lo siguiente: "Allá era una operación militar y acá es solo de adiestramiento. Acá tenés un Estado débil, mientras en Haití era inexistente. Pero la idea es la misma reforzó 'dar presencia al Estado' y no sabés cuánto lo agradece la gente” (Jorge Duarte, comunicación personal, 29.10.2019). Al mismo tiempo, el Ejército desplegó en la zona sus radares móviles de alcance terrestre, de acuerdo a la orientación de Gendarmería asentada en la ciudad de La Quiaca, y en forma permanente orientó la ubicación y movimiento de esos radares. Para Gendarmería, la información provista por ese medio ha sido una ayuda: les permitió rastrear la circulación por los cientos de caminos secundarios de la región, de camionetas que supuestamente transportaban drogas ilícitas.

9. Las operaciones psicológicas fueron prohibidas en 2006, luego de conocerse que en la Base Naval Almirante Zar en Trelew se recogía información de políticos y organizaciones sociales con fines de inteligencia, hecho prohibido por la Ley de Inteligencia Nacional sancionada en 2001. Desde entonces, las acciones cívicas son comprendidas por la doctrina bajo la denominación de Comunicación Social Asociada al Combate. 
Dos meses después del despliegue, el Ministerio de Defensa difundió por medios periodísticos las tareas que realizó el Ejército de modo escueto al referirse a la "instrucción militar de combate en el ambiente específico", "instrucción de operación de radares" e "instrucción de patrullas de combate y ejercicios de tiro". Pero usó muchas más palabras para describir el apoyo a la comunidad, tal como se lee en este artículo periodístico:

Uso de máquinas viales en tareas de mantenimiento de caminos y zanjeo en La Quiaca; (...) obras de mejoramiento de las instalaciones del aeropuerto de esa ciudad; (...) trabajos de mantenimiento y refacciones en escuelas de la Puna jujeñay decenas de tareas de apoyo a comunidades aborígenes de los departamentos de Yavi y Santa Catalina, como: la reparación de edificios comunitarios, construcción de tomas de agua y extensión de canales de riego, así como también distribución de materiales educativos a las escuelas de Tunalito, Ronque y Huachichocana. También se transportaron donaciones a una escuela de El Durazno, entre otras actividades. (Dinatale, 2018)

Cabe decir que en ningún caso el Ejército tomó contacto directo con las poblaciones aborígenes. Fue imprescindible hacerlo a través del Estado provincial, que sí contaba con interlocutores y funcionarias que procedían de esas comunidades. Pero, además, ese apoyo fue posible en la provincia de Jujuy porque su gobernador, Gerardo Morales, era un aliado del gobierno de Cambiemos. La funcionaria a cargo de la oficina de asuntos indígenas contribuyó con la confianza de los líderes de las distintas comunidades de la Puna hacia los militares, hasta en temas tan delicados como la colaboración del Ejército en la medición de las tierras para el registro de la propiedad comunitaria ante el Estado, tarea que debieron explicar con más cuidado, ya que la primera sospecha fue que se las quedaría el Ejército.

Como se puede observar, localmente, las tareas del Ejército no eran primeramente concebidas como de seguridad, sino como formas de avance de la soberanía estatal sobre la posesión de tierras comunales. La explicación de que fueran interpretadas como ayuda, está relacionada con la oficina del Estado provincial, de modo tal que se advierte otra forma de ejercicio de la soberanía preexistente a la llegada del OIN. Por esa misma razón, ninguna de estas tareas fue posible en provincias cuyos gobernadores no eran aliados del Gobierno nacional. Todo lo cual muestra que la no presencia del Estado pertenece al terreno de la declamación y, con ello, se ve que el OIN era un ensayo de una forma alternativa de ejercicio de la soberanía o bien un medio de refuerzo de la soberanía ejercida a través de otras políticas estatales.

Hasta mediados de 2019, el Ejército permanecía desplegado bajo el OIN. Si bien las notas y comunicados oficiales mantenían el número de 500 militares desplegados, según datos de la Gendarmería solo había unos 130 en la zona de La Quiaca, 
y un puñado menos numeroso en la región del Chaco. Esto indica también que la declamación es un recurso de una soberanía que no consigue alcanzar en el plano concreto lo que promete narrativamente. En rigor, tampoco su diagnóstico se corresponde con el orden concreto. La cosmovisión gubernamental no parece requerir ajustarse a lo concreto.

\section{Conclusiones}

El propósito de este artículo fue mostrar cómo el proceso conocido como militarización de la seguridad tuvo continuidades más allá de la discontinuidad político-partidaria de los gobiernos de centro-izquierda y de centro-derecha que se sucedieron en Argentina, en las dos primeras décadas del siglo XXI. Esa continuidad, vista en un sentido positivo, indica que los gobiernos han echado mano de tecnologías operadas por militares y, posteriormente, de patrullas de militares para recuperar una soberanía que no dejan de declarar dañada, fragilizada, debilitada. La impotencia del Estado para frenar el tráfico de personas y mercancías ha sido una condición clave del recurso a tecnologías de vigilancia operadas por militares, y mayor presencia de lo estatal encarnada en ellos. Este despliegue que limitó el uso de la fuerza no significó una disminución del tráfico, sino un endurecimiento de los controles y un aumento de los decomisos, cuyos esperados efectos en el desaliento del negocio vienen siendo fallidos.

La militarización, entonces, puede remitirnos a procesos dispares. En Argentina, encontramos relaciones de complementariedad y distinción, entre las formas de ejercicio de la soberanía nacional. En otros términos, el uso político del instrumento militar en el propio territorio es tanto un recurso de gobierno en espacios declarados en los márgenes de la soberanía estatal como un modo de reconstituir o deconstruir al propio Estado desde sus márgenes.

En ese proceso, el Ejército buscó además transitar, en el propio territorio, desde una doctrina propia de la Guerra Fría hacia una de la posguerra fría, ya ensayada en Haití. Este proceso no fue solo producto de la adopción de modelos producidos en el Comando Sur, sino que hubo reapropiación de una experiencia nacional ejercida fuera de los límites de la propia soberanía. Sin lugar a dudas, las condiciones domésticas han propiciado esa reapropiación de las misiones de paz por parte del EMCO en un sentido democratizador, si por este entendemos máxima abstención en el uso de la fuerza pública. Para el Ejército, el OIN era un modo de reintegrarse en la comunidad brindando un servicio a cambio de legitimidad, aunque fuera en pequeña escala, reforzando, a través suyo, la presencia del Estado. También suponía recuperar el reconocimiento de su papel en la construcción mítica del Estado Nación. 
Finalmente, el OIN no fue ajeno a la influencia global que impone sobre los límites nacionales una idea de frontera peligrosa, sitio de las amenazas trasnacionales como el terrorismo y el narcotráfico. En la reproducción de esa visión, el Estado nacional no solo se militariza, también se torna impotente y precario. A la vez, esas amenazas globales son reapropiadas en escenarios locales, para hacer con ellas cosas parecidas, pero no idénticas, de manera que el recurso a los militares durante la posguerra fría, en contextos particulares de democratización, nos ofrece una vía de entrada apta para entender, en tiempos de pulverización del Welfare State, la deconstrucción y reconstitución del Estado nacional en regiones periféricas del capitalismo global.

\section{Referencias}

Agamben Giorgio (1998). Homo Sacer: Sovereign Power and Bare Life. Stanford: Stanford University Press.

Aguilera, Edgardo (4 de enero de 2016). Expiró plan de control fronterizo antinarco. Ámbito. Recuperado de https://www.ambito.com/expiro-plan-control-fronterizo-antinarco-n392209

Calveiro, Pilar (2012). Violencias de Estado. La guerra antiterrorista y la guerra contra el crimen como medios de control global. Buenos Aires: Siglo XXI.

Centro de Estudios Legales y Sociales (2018). La guerra interna. Cómo la lucha contra las drogas está militarizando América Latina. Buenos Aires: CELS. Recuperado de https://www.cels. org.ar/militarizacion/pdf/laguerrainterna.pdf

De Jong, Ingrid (2015). El acceso a la tierra entre los indios amigos de la frontera bonaerense (1850-1880). Revista de Ciencias Sociales, 87(27), 87-117.

De Oliveira, Joao Pacheco (2014). Pacificação e tutela militar na gestão de populações e territórios. MANA, 2O(1), 125-161. Recuperado de http://www.scielo.br/scielo.php?pi$\mathrm{d}=$ So104-93132014000100005\&script=sci_abstract\&tlng=pt

Dinatale, Martín (6 de noviembre de 2018). El Gobierno traslada otros 500 militares para el operativo de la frontera norte. Infobae. Recuperado de https://www.infobae.com/politica/2018/11/o6/el-gobierno-traslada-otros-50o-militares-para-el-operativo-de-la-frontera-norte/

Dirección Nacional de Migraciones (s.f.). Panorama Movimientos Migratorios 2017. Recuperado de http://www.migraciones.gov.ar/pdf/estadisticas/movimientos_migratorios_2017.pdf

Frederic, Sabina (2015). Modos de dar seguridad, adaptación y obediencia en el escenario de re-despliegue territorial de la Gendarmería Nacional Argentina. Estudios, 32, 219-241. https://doi.org/10.31050/1852.1568.n32.11592 
Frederic, Sabina (2019). Ni policías ni militares: obediencia, resistencia y rebeldía de gendarmes en operaciones urbanas de Buenos Aires. Desacatos, 60, 12-33. Recuperado de http:// desacatos.ciesas.edu.mx/index.php/Desacatos/article/view/2088

Frederic, Sabina; Hirst, Mónica (2016). La presencia de Argentina en Haití: contexto global, regionaly experiencia militar (2004-2015). Buenos Aires: Teseo.

Gaik-Aldrovandi, Mariano (2 de abril de 2019). Los “bagayeros": el trasfondo del ataque contra Patricia Bullrich y Juan Manuel Urtubey. Clarín. Recuperado de https://www.clarin.com/ policiales/bagayeros-trasfondo-ataque-patricia-bullrich-juan-manuel-urtubey_o_eTF7oDR--.html

Gallo, Daniel (9 de septiembre de 2013). Un vacío legal se abre frente al despliegue de militares en el Norte. La Nación. Recuperado de https://www.lanacion.com.ar/seguridad/un-vaciolegal-se-abre-frente-al-despliegue-de-militares-en-el-norte-nid1618156

Hansen, Thomas B.; Stepputat, Finn (2006). Sovereignty Revisited. The Annual Review of Anthropology, 35, 295-315. https://doi.org/10.1146/annurev.anthro.35.081705.123317

Kessler, Gabriel (2013). Ilegalismos en tres tiempos. En Individuación, precariedad, inseguridad ¿Desinstitucionalización del presente? (pp. 109-165), editado por Robert Castel; Gabriel Kessler; Denis Merklen; Numa Murard. Buenos Aires: Paidós.

Lima, Antonio Carlos de Souza (2002). Gestar e gerir. Estudos para uma antropologia da administração pública em Brasil. Rio de Janeiro: Relumé Dumará.

Ministerio de Seguridad (25 de julio de 2011). Comenzó el operativo Escudo Norte. Recuperado de https://www.argentina.gob.ar/noticias/gcomenz\%C3\%B3-el-operativo-escudo-norte

Procuración Penitenciaria de la Nación (2019). Informe anual 2018: la situación de los derechos humanos en las cárceles federales de la Argentina. Buenos Aires: Procuración Penitenciaria de la Nación.

Ratto, Silvia (2003). Cuando las "fronteras" se diluyen. Las formas de interrelación blancoindio en el sur bonaerense. En Las fronteras hispanocriollas del mundo indígena latinoamericano en los siglos XVIIy XIX (pp. 199-232), compilado por Raúl J. Mandrini; Carlos D. Paz. Tandil: IEHS/CEHIR/UNS.

Renoldi, Brigida (2015). Estados posibles: travesías, ilegalismos y controles en la Triple Frontera. Etnográfica, 19(3), 417-444. Recuperado de https://journals.openedition.org/etnografica/4049

Sain, Marcelo (2018). ¿Los militares como policías? Cambios en la seguridad en Argentina, 2013-2018. Nueva Sociedad, 278. Recuperado de https://nuso.org/articulo/los-militares-como-policias-seguridad-en-argentina-2013-2018/ 
Sistema Argentino de Información Jurídica (2019). Sistema Nacional de Estadísticas sobre Ejecución de la Pena. Recuperado de http://www.saij.gob.ar/estadisticas-ejecucion-de-la-pena

Sotomayor, Arturo C. (2013). The Myth of the Democratic Peacekeeper: Civil-military Relations and the United Nations. Baltimore: Johns Hopkins University Press.

Souto-Zabaleta, Mariana; Delfino, Paula; Sarti, Silvio Sebastián (2019). Consideraciones críticas sobre el abordaje del problema del narcotráfico en Argentina. Revista del Instituto de Ciencias Jurídicas de Puebla, 13(44), 51-88.

Tokatlian, Juan G. (2017). Quéhacer con las drogas. Una mirada progresista sobre un tema habitualmente abordado desde el oportunismo politico y los intereses creados. Buenos Aires: Siglo XXI.

Un escudo contra los narcotraficantes (21 de julio de 2011). Página 12. Recuperado de https:// www.pagina12.com.ar/diario/sociedad/3-172726-2011-07-21.html

Wacquant, Loic (2000). Las cárceles de la miseria. Buenos Aires: Manantial. 